\title{
Anger and Advancement Versus Sadness and Subjugation: The Effect of Negative Emotion Expressions on Social Status Conferral
}

\author{
Larissa Z. Tiedens \\ Stanford University
}

\begin{abstract}
Four studies examined status conferral (decisions about who should be granted status). The studies show that people confer more status to targets who express anger than to targets who express sadness. In the 1st study, participants supported President Clinton more when they viewed him expressing anger about the Monica Lewinsky scandal than when they saw him expressing sadness about the scandal. This effect was replicated with an unknown politician in Study 2. The 3rd study showed that status conferral in a company was correlated with peers' ratings of the workers' anger. In the final study, participants assigned a higher status position and a higher salary to a job candidate who described himself as angry as opposed to sad. Furthermore, Studies 2-4 showed that anger expressions created the impression that the expresser was competent and that these perceptions mediated the relationship between emotional expressions and status conferral.
\end{abstract}

Every real leader knew that the occasional outburst of unexplained anger was good...

- Tom Wolfe, A Man in Full

In Tom Wolfe's novel, A Man in Full, the business tycoon protagonist loses much of the power and status he spent his life attaining. In his quest to maintain what status remains and reclaim what has been lost, he ponders his philosophy of leadership. As reflected in the quotation above, he believes that expressions of anger can bring power and status.

Individuals vary in how much they desire status and power (Winter, 1973), but the motivation to have influence and be recognized as valuable is widespread (Brown, 1985; Frank, 1985; Lonner, 1980). The quest for status influences a myriad of interpersonal phenomena, from dyadic relationships to the interactions of nations (Frank, 1985). However, there is little research on what strategies are most successful in attaining status. Current research does not establish whether the philosophy of Wolfe's character helped propel him to the top, contributed to his downfall, or whether a relationship between anger and status attainment is mere fiction.

In this article, I take a functionalist approach to emotions and examine whether a target's negative emotion expressions influence people's decisions about whether the target should be given status and power (i.e., status conferral). The focus is on the effects of

The research presented in this article was supported by the Stanford Graduate School of Business.

Many thanks go to Greg McHugo, Nancy Nelson, Michele Tugade, and Michael Zuckert, without whom this research could not have been completed. Study 3 was only possible through the generosity of the anonymous company who allowed me to study them. I am also grateful to John Jost. Fiona Lee, Susan Linton, and Michael Morris for helpful comments on drafts of this article.

Correspondence concerning this article should be addressed to Larissa Z. Tiedens, Graduate School of Business, Stanford University, Stanford, California 94305-5015. Electronic mail may be sent to 1tiedens@leland standford.edu. negative emotions because changes in stratification are more likely following negative events than positive events. Negative events encourage people to examine their surroundings carefully (Clore, Schwarz, \& Conway, 1994; Wong \& Weiner, 1981) and lead people to question whether the current hierarchy should be changed (Marcus \& Mackuen, 1993). Thus, an individual's reactions to negative events might play a role in whether others believe that individual is worthy of status. One common reaction to negative events is the expression of negative emotions. These studies compare negative emotions with each other rather than with a neutral or a positive state to assure that the findings represent the effects of the specific emotion rather than the effects of emotionality or negativity in general.

Social psychologists and sociologists alike have distinguished among various ways of exercising power. Although different theorists have suggested different numbers of categories, or types, of influence, one dichotomy repeatedly appears. One type of power or influence has been called coercion, intimidation, punishment centered, involuntary, and imposed (Dornbusch \& Scott, 1975; French \& Raven, 1959; Jones \& Pittman, 1982; Kelman, 1961; Weber, 1947). In this domain of social influence, people publicly comply with the wishes of the influencer to avoid punishment. This type of influence is not particularly stable. People only do as the coercive influencer wishes to the extent that the power holder can observe their behavior and deliver punishments. The coercive influencer is not respected and is not followed voluntarily. This type of influence can be contrasted with another type: legitimate, voluntary, or endorsed power. Legitimate power occurs when a target has status and can influence others because people privately believe that the target deserves such a position. The legitimate power holder does not have to persuade and coerce subordinates at every turn. Subordinates follow the directions voluntarily and out of respect for the leader and the leader's position. For these reasons, legitimate power tends to be more stable (Blau, 1956).

The term status conferral refers to actions that provide status or legitimacy to a target. The process of status conferral is necessarily interpersonal. After perceiving a target, individuals decide whether 
the target deserves status, and if so, they must behave in a way to provide or confer status on the target. Status conferral of some type occurs in all stratified groups, but the behavior that defines status conferral depends on the organization, group, or situation. In democracies, votes confer status; in business organizations, promotion decisions constitute status conferral. In other circumstances, there are more subtle signals of status conferral, such as nonverbal and verbal deference signals (cf. Ellyson \& Dovidio, 1985; Keltner, Young, \& Buswell, 1997). In this research, voting and promotion decisions are examined.

Several literatures are germane to the question of which negative emotions result in status conferral, including classic theory on impression management and social influence and recent research on trait inferences that result from emotion expressions. It is interesting to note that these literatures make divergent predictions about which emotions could be used to attain status.

\section{Anger, Intimidation, and Status Conferral}

Work in the area of impression management lends support to the idea that anger expressions could be a successful social influence strategy. Jones and Pittman (1982) argued that the goal of all strategic impression management is "the augmentation or protection of the strategist's power to influence and control his social environment" (pp. 248-250). Therefore, the goal to acquire status and power is the essence of impression management. Among various strategies, intimidation strategies are those that convince others to do as the strategist wishes through implicit or explicit threats and warnings. Clark, Pataki, and Carver (1996) argued that anger expressions are an intimidation strategy. Anger expressions create the impression that the expresser is strong and persuade others to comply with the expresser.

Both anecdotes and systematic studies suggest that anger is intimidating and that expressions of it can create compliance in others. Bill collectors strategically express anger to get debtors to pay (Hochschild, 1983; Sutton, 1991). Negotiators purposely expose flashes of anger as a tactic to claim value (Adler, Rosen, \& Silverstein, 1998). Parents use anger to control their children (Bugental, 1998), and the anger expressed by school yard bullies serves as a reminder of their willingness to do physical harm to get their way (Olweus, 1978).

Although anger gains immediate compliance, its long-term effect on status is less certain. Bullies, for example, often rule the schoolyard but rarely attain positions of high status in their adult lives (Caspi, Elder, \& Bem, 1987). In general, it is unlikely that the threats of violence that often accompany anger expressions could propel a person to the top. Achievement of status within complex social hierarchies does not rest solely on the ability to push others out of the way. Instead, status is gained and maintained when the other members of the group are complicit rather than coerced. Similar to other social influence situations, compliance merely signals initial public acceptance, but lasting effects require internalization (Kelman, 1961). Therefore, to be useful in the long term, anger cannot merely intimidate; it must also suggest to group members that the expresser deserves to be valued and respected.

\section{Characteristics Ascribed on the Basis of Emotional Expressions}

Expressions of emotions affect beliefs about the expresser. People infer what emotion a person is feeling on the basis of facial expressions, voice intonation, and behavior (Banse \& Scherer, 1996; Ekman, 1993). Once people identify a target's emotion, they infer other characteristics about that person. For example, belief that a target is happy results in increased liking. Sadness results in the perception that the expresser is in need of help, weak, submissive, and incompetent but also that the expresser is likable, warm, and nice. Expressions of embarrassment and guilt communicate an admission of wrongdoing and a willingness to make amends (Keltner \& Buswell, 1997; Keltner et al., 1997). People expressing anger are seen as dominant, strong, competent, and smart but also less warm, friendly, and nice (Clark et al., 1996; Gallois, 1993; Labott, Martin, Eason, \& Berkey, 1991). Therefore, the evidence suggests that the expression of negative emotions creates complex social impressions that are neither entirely negative nor entirely positive. Rather, sadness, guilt, and embarrassment seem to enhance a target's socio-emotional characteristics, whereas anger enhances task-oriented characteristics.

Emotional expressions also affect perceptions of social positions. People believe individuals with angry facial expressions occupy more powerful social positions than do individuals with sad facial expressions (Keating, 1985). Similarly, Tiedens, Ellsworth, and Mesquita (2000) found that participants who read a vignette about two characters believed that the character described as angry was high status and that the character described as sad and guilty was low status. Thus, people seem to believe that emotional expressions are diagnostic of the social position of the expresser. In the current research, I test the more radical proposition that emotional expressions influence people's perception of what position the target should occupy. Specifically, the studies presented here examine whether people believe that a target who expresses anger deserves more status and power than does a target who expresses sadness.

A question inherent to the relation of emotion to status conferral is whether people provide status and power to someone they like or to someone they think is competent. Existing literature is inconclusive on this issue. Considering status attainment as a popularity contest where liking matters implies that expressions of sadness are the most fruitful response to negative events. However, if perceptions of competence are more heavily weighted in decisions about who deserves status and power, expressing anger would be a more effective tactic.

The four studies presented in this article test whether anger or sadness expressions facilitate status conferral in two different contexts. The first two studies examine status conferral in political contexts, and the second two in business settings. These studies also look at whether emotion expressions affect impressions of niceness and competence and investigate the role these impressions play in status conferral.

\section{Study 1: The Effects of President Clinton's Emotion Expressions on Support for Impeachment}

The status-related impressions created by emotion expressions were widely and publicly discussed during the Monica Lewinsky 
scandal that almost deprived President Clinton of power. Not only was Clinton criticized for his relationship with Lewinsky but many thought he did not handle his image well once the details became public. It was often suggested that Clinton should be more apologetic and express more guilt and sadness. However, although Clinton made a few brief apologies, the most salient image was of him angrily wagging his finger.

Research has shown that politicians' emotions can influence the affective responses of people who watch them (Lanzetta, Sullivan, Masters, \& McHugo, 1985). When politicians express positive emotions, viewers feel more positively than when politicians express negative emotions (McHugo, Lanzetta, Sullivan, Masters, \& Englis, 1985). Even more important for the questions addressed here, people's reactions differed depending on what specific negative emotion was expressed. Participants felt more positively following politicians' expressions of anger and threat than they did after politicians' expressions of fear and evasion. Although these studies measured affect following a politician's affective display rather than support for the politician, other research has shown that positive affect toward a politician predicts support (Abelson, Kinder, Peters, \& Fiske, 1985).

Little research has examined how politicians' emotional expressions affect people's attitudes about particular events or perceptions of the abilities and character of the politician (Glaser \& Salovey, 1998). Even less research has examined whether emotions might play a role in why some politicians seem irreparably harmed by scandal, whereas others emerge unscathed. One possibility is that politicians' emotional expressions about scandals influence the public's response to the scandal and, ultimately, their support for the politician. If so, then emotion expressions can function to enhance, preserve, or reduce a politician's power and status following a political scandal. This study examines whether emotion expression can affect a politician's status by examining responses to Clinton's expressed emotions about the Lewinsky scandal.

\section{Method}

\section{Participants}

Fifty-four students (20 men and 34 women) participated in this study in small, randomly assigned groups (10-15 people). Twenty-nine participants were in the anger condition, and 25 were in the sad condition

\section{Materials}

Video clips. Participants watched one of two video clips. Both clips were extracted from Clinton's grand jury testimony about the Lewinsky scandal, originally given on August 17, 1998 (Grand jury testimony of William Jefferson Clinton, 1998). I chose two short segments on the basis of displayed emotions. In the 47-s angry clip, Clinton talked about what he perceived to be the cause of the entire investigation. He said that the behavior of Paula Jones' lawyers was inappropriate, wrong, and unfair. As Clinton talked, he looked straight into the camera (i.e., direct gaze) and emphasized his points with strong hand gestures. He appeared angry during this clip. During the 45-s sad clip, Clinton discussed another cause of the entire investigation. He said that his relationship with Monica Lewinsky was inappropriate and that the relationship had been wrong. While he spoke, his head was hung and his gaze averted, as is typical for those expressing sadness and guilt (Ekman \& Friesen, 1975).
Questionnaires. After watching one of the videos, participants filled out a brief questionnaire on which they provided demographic information, indicated their attitudes about impeachment, and rated Clinton's emotions.

The demographic information collected included the participant's age, gender, nationality, ethnicity, political party affiliation, degree of identification with political party (on an 11 -point scale ranging from $1=$ not at all to $11=$ very strongly), number of elections participated in, and number of elections held in which the participant was eligible to vote (i.e., number held during which he or she was 18 years old or older).

The attitudinal section was designed to assess the degree to which the participants believed that Clinton should maintain his position of status and power versus being removed from that position. In this section, the participants rated their approval of Clinton, the Democrats, and the Republicans on 11-point scales ranging from 1 (not at all) to 11 (completely). They also used 11-point scales ranging from 1 (completely disagree) to 11 (completely agree) to indicate their agreement with the following statements: "Clinton should be removed from office" (reverse scored), "The House Judiciary committee was wrong to impeach Clinton," "Clinton should be allowed to remain president," "The Senate should find Clinton guilty" (reverse scored), "Clinton should be severely punished for his behavior" (reverse scored), "Clinton should resign" (reverse scored), and "The impeachment matter should be dropped."

Finally, the participants rated Clinton's emotions during the film clip. Again, these ratings were made on 11-point scales ranging from 1 (not at $a l l)$ to 11 (extremely). Anger and sadness were included on this list, and these ratings were used as manipulation checks.

\section{Procedure}

These data were collected in the first week of February 1999. The House Judiciary committee had passed the articles of impeachment, and the Senate had just begun its debates about whether Clinton should be found guilty. The experimenter told the participants that this was a study of attitudes about Clinton and the recent scandal. The participants were told that the videotape was to remind them of some of the issues. The participants watched one of the videotapes and then filled out the questionnaire. A week later, they were debriefed. In this discussion, they were first asked their opinions about the scandal and their predictions for the study. Finally, the experimenter told them the hypotheses and background of the experiment.

\section{Results}

\section{Manipulation Check}

Participants thought that Clinton expressed more anger $(M=8.21, S D=1.78)$ than sadness $(M=4.76, S D=2.63)$, $t(52)=5.70, p<.001$, in the anger clip and more sadness $(M=7.48, S D=2.38)$ than anger $(M=3.24, S D=1.74)$, $t(52)=7.52, p<.001$, in the sad clip.

\section{Support for Clinton}

The attitude questions were combined into a single variable to indicate how much the participants believed that Clinton should maintain his status and power $(\alpha=.90)$. There were no main or interaction effects for political identification or gender, so the data were collapsed across these variables. A one-way analysis of variance (ANOVA) indicated that the video clips affected the participants' attitudes about Clinton's future, $F(1,52)=7.32, p<$ .01. Participants who viewed the anger clip were significantly more pro-Clinton $(M=73.31, S D=18.29)$ than were those who viewed the sad clip $(M=58.32, S D=22.42)$. It is interesting to 
note that when the participants were debriefed, they said, just as the national media had, that Clinton would be best served by expressing sadness rather than anger.

\section{Discussion}

These results support the notion that people give more power and status to someone who expresses anger than to someone who expresses sadness, even when the outcome is real and important. However, specifics about this real political event may have contributed to these results. The public outrage over this scandal may have led participants to believe that anger was the most appropriate emotion. However, the debriefing discussion did not support this interpretation. Another possibility is that anger was a successful strategy in this situation because of Clinton's status and power. Jones and Pittman (1982) argued that intimidation strategies are only successful for people who have power and status; thus, it might not have these effects for people who do not happen to be world leaders.

In addition, an alternative explanation exists for this study. In these tapes, Clinton differed not only in which emotions he expressed but also in what he said. These content differences may have been what led to the different reactions. Therefore, although this study had high external validity, the internal validity was low. Clearly, more controlled studies in which emotion displays are not confounded with content and to which people do not bring so many previously formed attitudes are necessary.

\section{Study 2: The Emotional Expressions of an Unknown Political Candidate}

This study addresses some of the limitations of the first study. In Study 2, videotapes were created in which the expressed emotions of the politician varied but the content remained constant. Furthermore, although the Clinton study showed strong effects of emotional expression on status maintenance, it did not examine status mobility, nor did it provide any information about why anger might have such beneficial effects. Study 2 examines whether trait perceptions mediated the effect of emotional expressions on status conferral. Previous research has shown that perceived competence is one of the most important trait characteristics in people's determination of whether to support a politician. Politicians who are seen as competent recover from scandals better (Funk, 1996), are evaluated more favorably (Funk, 1997), and are more likely to be a vote choice (Kinder, 1986). However, so far there is no evidence that a politician's expressed anger can create the impression of competence and, in doing so, increase that politician's access to power and status. In this study, not only did participants indicate their support for the politician, they also rated their impressions of him, which allowed for an examination of whether competence impressions mediate the effects of expressed anger.

\section{Method}

\section{Participants}

Students in a political philosophy class at a midwestern university participated in this study on a volunteer basis. Seventy-six students (46 men, 29 women, and 1 who did not specify gender) completed the questionnaire. Assignment to conditions was based on section enrollment.
Although this was not strictly random assignment, there were no differences between the sections (and therefore between conditions) in gender makeup, political party affiliation, number of elections participated in, ethnic composition, age, or the percentage of students choosing to participate in the study (95\% in both sections).

\section{Materials and Procedure}

Video clips. Two videotapes were made for the purposes of this study. Each was $1 \mathrm{~min} 20 \mathrm{~s}$ long. The same actor delivered the speech on terrorism using exactly the same words in the two clips. The actor was instructed to deliver the speech in an angry way in one tape and in a sad way for the other tape. The actor-politician claimed that the face of terrorism has changed because it is now sponsored by national governments and that this sponsorship has resulted in more deaths, greater destruction, and less peace. I chose terrorism because it is a current topic of concern and because both anger and sadness are appropriate emotions to express while discussing it.

Questionnaire. Participants provided the same demographic information they did in the previous study. They used 11-point scales to rate how likely they would be to vote for the speaker, how good his speech was, how good he would be at solving economic problems and at managing international relations, and how much he would improve the country. They also rated the speaker on trait semantic differential scales, including ratings of incompetent-competent, knowledgeable-ignorant (reverse scored), coldwarm, and likable--not likable (reverse scored). The first two traits tap into the dimensions of competence $(\alpha=.93)$, whereas the second two capture warmth ( $\alpha=.72)$. Then the participants indicated how typical and appropriate the speech was. Finally, they rated the emotional expressions of the speaker. The entire procedure (watching the tape and answering the questions) was completed in $15 \mathrm{~min}$.

\section{Results}

\section{Manipulation Checks}

Ratings of the politician's emotions indicated that the actor conveyed the intended emotions. The politician was rated as more angry in the angry clip $(M=5.47)$ than in the sad clip $(M=2.80)$, $F(1,64)=25.99, p<.001$. The politician in the sad clip was rated as more sad $(M=5.03)$ than the politician in the angry clip $(M=3.42), F(1,64)=7.74, p<.01^{\prime}$

The other concern about the tapes was whether the emotions were equally appropriate to the topic and to political speeches in general. To examine this, I had the participants rate the speech both on typicality and on appropriateness. No reliable differences were found between the conditions on typicality, $t(74)=1.41, n s$, or appropriateness, $t(74)=1.07, n s$. These comparisons indicate that it is unlikely that any differences between the angry and sad conditions were due to differences in how appropriate it was to express these emotions in this context.

\section{Status Conferral}

The participants indicated their willingness to confer status on the politician by answering two types of questions. First, participants rated how likely they would be to vote for him for president. This was the most direct measure of status conferral. Furthermore,

\footnotetext{
${ }^{1}$ Ten participants did not rate the emotions of the politician. The nonresponses were approximately evenly distributed across conditions; 4 were in the sad condition and 6 were in the angry condition.
} 
the participants rated the politician along several dimensions in terms of how good of a political leader he would be. There were no main or interaction effects on the voting measure or the political leadership variable due to the participants' gender or political affiliation, so the data were collapsed across these variables.

Voting for the speaker. The participants indicated that they would be more likely to vote for the politician when they saw the angry tape $(M=5.00, S D=1.96)$ than when they saw the sad tape $(M=3.70, S D=1.53), F(1,74)=9.83, p<.01$.

Political leadership. The political leadership questions were summed into a single variable. A one-way ANOVA indicated that the participants believed that the politician would be a better political leader when they saw the anger clip $(M=25.80$, $S D=7.75)$ than when they saw the sad clip $(M=18.79$, $S D=6.85), F(1,74)=25.80, p<.001$.

\section{Mediation of Trait Perceptions}

The political leadership variable and the voting variable were combined to create a single status conferral variable $(\alpha=.89)$. This composite was used as the dependent variable for an examination of whether trait perceptions mediate the relationship between emotion expressions and status conferral. Mediation would be indicated if (a) emotion expression influenced status conferral, (b) emotion expression influenced trait perceptions, (c) trait perceptions predicted status conferral, and (d) the relationship between emotion expression and status conferral was weaker when trait perceptions were accounted for (Baron \& Kenny, 1986).

Regression analyses indicated that emotion expressions affected trait perceptions. The politician was rated as more competent when angry than when $\operatorname{sad}(\beta=.42), t(74)=3.91, p<.001$. However, the angry target was rated as less likable $(\beta=-.27), t(74)=2.38$, $p<.05$. When emotion and competence were entered as predictors of status conferral, competence was significant $(\beta=.70)$, $t(73)=7.89, p<.001$, but emotion was not $(\beta=.12)$, $t(73)=1.42, p>.15$. When emotion and liking were used as simultaneous independent variables, emotion was a significant predictor $(\beta=.37), t(73)=3.31, p<.01$, but liking was not $(\beta=$ $-.18), t(73)=1.60, p>.10$. Thus, perceptions of competence fully mediated the relationship between emotion expression and status conferral, but perceptions of liking did not meet the third criterion of mediation and therefore did not mediate the relationship between emotion expression and conferring status.

\section{Discussion}

These results replicate and extend those from the first study. Again, there was evidence that people confer status on politicians who express anger rather than sadness. In this study, I further found that this relationship was mediated by perceived competence.

At least in this study, people seemed to base their decisions about whom to give status to on perceived competence rather than on likability. Some might argue, however, that competence plays a critical role in national politics but not in other status contests. Perhaps competence is more important than likability in national political status contests because of the nature of the future interaction between politicians and constituents. Very few people have much contact with their elected representatives. This feature of politics may make it more likely for people to select on the basis of task-related characteristics rather than socio-emotional ones, but this is not necessarily generalizable to other social hierarchies. Therefore, Studies 3 and 4 test whether anger expressions result in status conferral in a domain in which more interpersonal contact occurs: business organizations. Study 3 examines this question in an actual organization and, in doing so, provides external validity. Study 4 is a controlled experiment with high internal validity. Together, they provide convergent evidence for the power of anger in business settings.

\section{Study 3: Negative Emotion Expressions and Career Promotion}

\section{Method}

\section{Participants}

This study was administered in a department of a software company. Although the group comprised 50 people, only 24 people $(17$ men and 7 women) were willing to participate in all components of this study. ${ }^{2}$

\section{Materials and Procedure}

Emotion expressions and trait perceptions. The questionnaire was distributed at a department meeting. Participants rated everyone in the group on how frequently they expressed a variety of emotions (including anger and sadness) on 7-point scales ranging from 1 (never) to 7 (frequently). They also rated each coworker on how much they can learn from that person and how much social support he or she provides, again on 7-point scales (ranging from $1=$ not at all to $7=a$ lot and $1=$ none to $7=a$ lot, respectively). Although these questions had different wordings than did the trait ratings in the prior study, they also indicated the degree to which the target excels on task characteristics and socio-emotional characteristics. The ratings from all the participants were averaged, so that there was a single score for each target on each variable.

Status conferral. There were three measures of status conferral. The first two were provided by the participants. They reported the number of times they had been promoted at the company and their salary level $(1=$ under $\$ 35,000 /$ year, $2=\$ 35-70,000 /$ year, $3=\$ 70-105,000 /$ year, $4=$ over $\$ 105,000 /$ year). These two variables can be considered measures of past status conferral. In addition, the manager of the group provided information about likely future status conferral. Specifically, the manager used 7-point scales to rate how well each employee had done in the job, whether the employee should be promoted, whether the employee should be put in a leadership position, whether the employee should be pushed out of the organization (reverse scored), and whether the employee should be rewarded. These items were combined into a Likelihood of Promotion scale $(\alpha=.94)$.

\section{Results}

\section{Sadness}

Sadness expressions were not related to the degree to which the target was perceived as someone who can be learned from but

\footnotetext{
${ }^{2}$ This low participation rate was due to a variety of factors. First, the questionnaire was distributed in a meeting that was not attended by everyone. Five people did not want their manager to fill out an evaluation about them, and therefore important data on them was missing. The company did not allow me to collect information about the people who did not participate to find out whether there were systematic differences between those who participated and those who did not.
} 
were related to the degree to which the target was perceived as providing social support $(r=.40, p<.05)$. Neither sadness nor social support was related to any of the status conferral variables (all $r s<.31$ ).

\section{Anger}

Coworkers' ratings of the targets' anger expressions were related to the degree to which the target was perceived as someone from whom the participants can learn $(r=.73, p<.01)$ but were not related to the degree to which the target was perceived as providing social support. To examine whether anger was related to the status conferral variables and whether these relationships were mediated by perceptions of a task-oriented trait (the learn-from variable), a series of regression analyses were conducted. The results of these analyses are presented in Table 1. The data were highly supportive of the hypotheses. Both anger and the learn-from variable individually predicted each of the status conferral variables. However, when they were simultaneously entered as predictors, only the learn-from variable had a significant relationship with status conferral. Therefore, the learn-from variable fully mediated the anger-status conferral relationship. ${ }^{3}$ Although the causal structure of these relationships is uncertain in this study, the pattern is remarkable, given its consistency with the other studies and the fact that the status conferral data were provided by different sources than those that provided the emotion and trait perception data.

\section{Study 4: Negative Emotions in a Job Interview}

In job interviews, the applicant seeks status, and the interviewer must decide whether to confer status. Thus, job interviews are an ideal context in which to study the effects of status attainment strategies. Study 4 examines the effects of anger and sadness in a job interview context.

\section{Method}

\section{Participants}

The 91 participants (56 men and 35 women) were recruited from required business classes. Announcements were made in four classes

Table 1

Standardized Betas From Regression Models Examining the Mediation of the Anger-Status Conferral Relationship by the Degree to Which the Participants Learned From the Target

\begin{tabular}{lccc}
\hline \multicolumn{1}{c}{ Dependent variable } & Model 1 & Model 2 & Model 3 \\
\hline $\begin{array}{l}\text { Previous promotions } \\
\text { Anger }\end{array}$ & $.40^{*}$ & & \\
$\quad \begin{array}{l}\text { Learn from } \\
\text { Income }\end{array}$ & & $.52^{* *}$ & .03 \\
$\quad$ Anger & $.49^{*}$ & & -.10 \\
$\quad \begin{array}{l}\text { Learn from } \\
\text { Manager's predicted promotion }\end{array}$ & & $.73^{* * *}$ & $.80^{* *}$ \\
$\quad$ Anger & $.46^{*}$ & & .03 \\
$\quad$ Learn from & & $.62^{* *}$ & $.60^{*}$ \\
\hline
\end{tabular}

Note. In Model 1, anger was used as the sole predictor for the relevant status conferral variable. In Model 2, the learn-from variable was the sole predictor. In Model 3, anger and the learn-from variable were both used as predictors.

${ }^{*} p<.05 . \quad{ }^{* *} p<.01 . \quad{ }^{* * *} p<.001$. indicating times and locations for experimental sessions. Interested participants signed up to participate in one of the eight possible sessions. Each session was held in a classroom, and 10-15 students were present. The assignment of sessions to experimental conditions was randomly determined and resulted in 42 people in the angry condition and 34 people in the sad condition.

All participants were first-year students in a master's in business administration program. Their mean age was 26.5 years, and they had experience with and knowledge of business job interviews. These students had been interviewed an average of 17 times and had interviewed an average of 24 applicants. Furthermore, most of these students will interview candidates and make decisions about whom to hire in future jobs. Thus, their responses are likely to be representative of people performing these duties in businesses.

\section{Materials and Procedure}

The experimenter said that the purpose of the study was to examine negative questions in a job interview. The participants were told that interviewers often ask applicants questions that require the applicant to say something negative about himself or herself. The experimenter said that the research team had videotaped many job interviews and had excerpted instances of negative questions. The participants were asked to watch one of these and rate the applicant.

Each video clip lasted $1 \mathrm{~min} 25 \mathrm{~s}$. The scripts were nearly identical. In the beginning of the video, the applicant talked about how much he enjoyed his previous job. The interviewer then asked the applicant to describe a time when things did not go so well at this previous job. In both tapes, the applicant told the same story in the same way. He described a situation in which he and a coworker lost an important client through a series of mishaps mostly involving losing each other in traffic on the way to a meeting. At the end of the clip, the interviewer asked how the applicant had felt about the event at the time it happened. In one tape, the applicant answered that he had felt angry, whereas in the other tape, he said he felt sad and guilty about it. This sentence was the only diffetence between the two conditions. ${ }^{4}$

After watching one of the videos, participants filled out a rating form. On it, they provided demographic information, conveyed whether they would hire the applicant, and suggested a salary level for the applicant (open-ended format). Then they indicated how much status, power, independence, and rank they thought the applicant should have in the new job with ratings on an 11-point scale ranging from 1 (none) to 11 (a lot) and, finally, rated the applicant on the same traits as they did in Study 2 (incompetent-competent, knowledgeable-ignorant, cold-warm, likablenot likable), also on 11-point scales.

\footnotetext{
${ }^{3}$ In exploratory analyses, gender and the interaction of gender with emotion expressions were tested individually and in combination with each other and with the emotion variables for each status conferral measure. None of the coefficients involving gender were statistically significant in any of these analyses.

${ }^{4}$ Some research has suggested that guilt and sadness are associated with different causal attributions or agency appraisals (Smith \& Ellsworth, 1985 ). Sadness is associated with situational responsibility, whereas guilt is associated with self-responsibility. Thus, the use of the word guilt might have resulted in participants perceiving the speaker as more responsible for the negative event than they would have if only the word sad was used. To examine this possibility, 125 individuals were asked to read a short vignette and answer one question. The vignette was the same as the story told by the applicant in Study 4 of this article. The character in the vignette was described as feeling either angry, sad, or guilty. Then the participants were
} 


\section{Results}

\section{Variable Construction}

A status conferral variable was constructed from the ratings of how much status, power, independence, and rank the applicant should get in a new job ( $\alpha=.92)$. Additionally, the ratings of competence were combined with the ratings of ignorance (reverse scored) to create a competence measure ( $\alpha=.87$ ), and the ratings of warmth were combined with the ratings of not likable (reverse scored) to create a likable measure $(\alpha=.83)$.

\section{Status Conferral}

There were three measures of status conferral: (a) the dichotomous variable of whether the applicant should be hired or not, (b) the composite job-level variable, and (c) the open-ended assigned salary. Preliminary analyses showed that participant gender did not have main or interaction effects on these variables, so the data were collapsed across gender.

Contrary to the prediction, a chi-square test examining the relationship of the emotion of the applicant to the yes-no hiring question showed a preference for the sad applicant over the angry applicant, $\chi^{2}(1, N=91)=3.97, p<.05$. Although most people in both conditions said they would not hire the applicant, more people in the sad condition said they would hire the applicant (38\%) than did people in the angry condition (19\%).

The other status assignment variables did support the hypotheses. Participants thought that the angry applicant should get a higher status position $(M=18.19, S D=5.28)$ than the sad applicant $(M=15.31, S D=6.18), F(1,89)=5.62, p<.05$. In addition, they thought the angry applicant should get paid more $(M=\$ 53,700 /$ year, $S D=15,120)$ than the sad applicant $(M=$ $\$ 41,330 /$ year; $S D=11,360), F(1,89)=19.70, p<.001$.

\section{Mediation of Perceived Trait Characteristics}

The emotional expression of the applicant affected participants' ratings of competence $(\beta=.30), t(89)=2.99, p<.01$, and likability $(\beta=-.35), t(89)=-3.54, p<.01$. Competence ratings were correlated with status position ratings $(r=.43, p<.01)$, but liking ratings were not $(r=.09)$. When status position ratings were regressed only on emotion, the relationship was statistically sig-

asked to rate on a 7-point scale how responsible the character was for losing the client. The omnibus $F$ was marginally significant, $F(2$, $122)=2.85, p<.10$, but paired contrasts are more relevant. The angry character was seen as less responsible $(M=2.95)$ than was the sad character $(M=3.56), t(122)=2.04, p<.05$, or the guilty character $(M=3.57) t(122)=2.09, p<.05$. It is important to note that the sad and guilty characters did not differ, $t(122)=, 04$. The null effect of the comparison between sadness and guilt suggests that it was not problematic for sadness and guilt to be lumped together in Study 4. In other contexts, sadness and guilt might communicate different attributions, but in this context, they are indistinguishable in terms of their effects on perceived responsibility. The difference between these two emotions and anger is consistent with previous research on attributions and emotions (Smith \& Ellsworth, 1985) and consistent with the view presented here that anger communicates competence. One aspect of competence is not being the cause of negative outcomes. nificant $(\beta=.24), t(89)=2.37, p<.05$. When competence ratings and emotion were used as independent variables, the beta coefficient of competence perceptions was statistically significant $(\beta=.40), t(88)=3.97, p<.001$, but the coefficient for emotion expression dropped to .12 and was not significant $(p>.20)$. In a model in which emotion and liking ratings were used as independent variables, emotion significantly predicted status position $(\beta=$ $.31), t(88)=2.89, p<.01$, and liking was only marginally significant $(\beta=.19), t(88)=1.81, p>.05$. Therefore, once again, competence ratings but not liking ratings met all the criteria for full mediation of the emotion-status conferral relationship.

\section{General Discussion}

These four studies provide evidence that anger displays can lead to status conferral. Furthermore, the final three studies provide insight into why anger has this effect. Expressions of anger create the perception that the expresser is competent, and status is conferred on the basis of perceived competence. Although anger expressions also result in the perception that the expresser is unlikable and cold, likability was not related to status conferral. Therefore, angry displays do not fulfill all social goals; they are especially effective in attaining status.

These studies suggest that emotion expressions provide shorthand communication of traits. Anger communicates competence. Sadness communicates warmth. Communicating traits through emotion expression is subtler than articulated statements proclaiming the presence or absence of these traits, but this subtlety probably adds to the expressions' power. Because emotions are often seen as spontaneous and natural rather than as strategic or manipulative, people are less likely to question their validity and to attribute alternative motives to the expresser than they are when other forms of communication are used (Hochschild, 1983; Lutz, 1990). This folk theory of emotion provides the perfect context for the strategic use of emotion, because the best strategies are always those that are not recognized as such (Jones \& Pittman, 1982).

\section{Possible Boundary Conditions}

These studies show remarkable consistency with respect to the effects of anger displays on status conferral, but it is likely that there are boundary conditions of this phenomenon. These boundary conditions, which are of theoretical, practical, and methodological interest, may be features of the expresser, of the anger expressed, or of the situation in which it is expressed.

One feature of the expresser that deserves attention is the gender of the expresser. In Studies 1, 2, and 4, the expresser was male. In the third study, both genders were represented. Although gender did not affect the positive relation between anger and promotion in Study 3, it is possible that this null result was due to the small number of women involved in this study or to the specific environment of that company or the industry. Thus, it may be that these studies document how men's expressions of anger result in increases in men's status. Because anger is not considered typical or normative for women (Lerner, 1980) and because norm breaking often inhibits status attainment, it may be a less successful strategy for women.

The target's chronic level of anger expression may also affect whether anger results in status mobility. People differ in how much 
anger they regularly express (Halberstadt, 1991). The anger expressions of people who frequently express anger may receive quite different responses than do those of people who rarely express it. Study 3 tested how frequency of anger expression affects status mobility, and evidence for a linear relationship was found. However, this might change at the extremes. People may habituate to the anger of someone who constantly expresses anger and no longer make inferences on the basis of these expressions. Similarly, when someone who rarely expresses anger does so, it may be particularly salient and have a large impact.

The specific attributes of the anger expression may also affect the impressions it creates. In these studies, the anger expressions were rather muted versions of anger. It is possible that only calm anger creates the impression of competence and deservingness of status. Hysterical and violent renditions of anger might have very different effects. Additionally, the direction and timing of anger expressions probably contributes to their effect. In these studies, anger was not directed toward the person making the status conferral decisions but toward a third party. Anger directed at the status conferrer would likely be less successful. Similarly, randomly expressed anger may not have the same beneficial results. Rather, the expresser likely has to convince observers that a negative outcome has occurred and that he or she has been wronged.

Study 4 , the job interview study, suggested another timing issue. Participants preferred to hire the sad applicant, but the angry applicant was assigned to a higher status position. Perhaps anger is only useful once one is already part of a group or an organization. When trying to gain access, one might need to express emotions that signal submission, like sadness.

Studies 2-4 showed that one of the costs of anger expressions is that the expresser is perceived as less likable. However, in the business and political contexts examined in these studies, the likability of these targets did not affect status conferral. This is likely a feature of many hierarchies, but others may assign greater value to social relationships. For example, some researchers have suggested that women-owned businesses are more concerned with socio-emotional skills (Martin, Knopoff, \& Beckman, 1998). In these contexts, getting ahead may require being seen as likable. Similarly, entire national cultures have been described as interdependent (Markus \& Kitayama, 1991). People in these cultures may not associate anger with competence and may not view competence as the only or the most important trait for leaders to possess. Thus, the effects of emotion expressions may differ in these environments.

\section{Conclusions}

Although some have argued that hierarchy is the most efficient group structure (Sidanius, 1993), it continues to have a bad reputation, at least among Americans (Fiske \& Depret, 1996). Whether or not hierarchy is inherently good or evil, it will likely continue to be an organizing structure of group life (Lonner, 1980), and, thus, understanding the psychological processes that contribute to it is important. These studies elucidate one process through which people confer status and power. Expressions of anger result in the conferral and, thus, the attainment and maintenance of status. The relationship of anger to status conferral may contribute to the bad reputation of hierarchies. Like hierarchies, anger tends to be con- sidered dangerous (Tavris, 1989). Also, the linking of anger and high status may support other negative components of hierarchy, such as the tendency of those with power to be corrupt (Kipnis, 1972). Indeed, the tendency of people to confer status on people who express anger may represent a dangerous bias. In Studies 1, 2, and 4 , there were no objective differences in the competence level of the sad target and the angry target. However, people used anger expressions as a signal of competence and the ability to wield power. When people rely on anger as a signal when making status conferral decisions, they reward expressions of anger, which may make anger expression even more likely in the organization, especially by high-status people. This could result in more aggressive and unpleasant organizational and group experiences.

However, anger may not have purely deleterious effects. Argyris (1994) argued that the expression of negative emotions is critical for communication and learning within a group. Among negative emotions, anger is particularly powerful in communicating what is wrong (Tavris, 1989). It may be just as the participants in Study 3 believe: People who express anger are also the ones who teach others. Thus, expressed anger likely has both positive and negative consequences for the hierarchies in which it occurs.

There are a number of details about the role of anger in status mobility that need attention in future research, but these studies make the initial basic step of showing that anger expressions can result in status conferral. The present set of studies demonstrates this process in two important contexts: politics and business. In doing so, these studies highlight the social nature of emotions. The expressions of emotion can facilitate social goals. Two of the most basic social motives are building relationships and obtaining status and power. These studies showed that emotions can function to fulfill both of these goals and that different emotions are associated with each of these goals.

\section{References}

Abelson, R. P., Kinder, D. R., Peters, M. D., \& Fiske, S. T. (1985). Affective and semantic components in political person perception. Journal of Personality and Social Psychology, 42, 619-630.

Adler, R. S., Rosen, B., \& Silverstein, E. M. (1998). Emotions in negotiation: How to manage fear and anger. Negotiation Joumal, 14, 161-177.

Argyris, C. (1994, July-August). Good communication that blocks learning. Harvard Business Review, 77-85.

Banse, R., \& Scherer, K. R. (1996). Accoustic profiles in vocal emotion expression. Journal of Personality and Social Psychology, 70, 614-636.

Baron, R. M., \& Kenny, D. A. (1986). The moderator-mediator variable distinction in social psychological research: Conceptual, strategic, and statistical considerations. Journal of Personality and Social Psychology, 51, 1173-1182.

Blau, P. M. (1956). Bureaucracy in modern society. New York: Random House.

Brown, R. (1985). Social psychology (2nd ed.). New York: Free Press

Bugental, D. B. (1998, June). Powerless parents use high levels of force. Paper presented at the meeting of the Society for the Psychological Study of Social Issues, Ann Arbor, Michigan.

Caspi, A., Elder, G. H., \& Bem, D. (1987). Moving against the world: Lifecourse patterns of explosive children. Developmental Psychology, 23, 308-313.

Clark, M. S., Pataki, S. P., \& Carver, V. (1996). Some thoughts and findings on self-presentation of emotions in relationships. In G. J. O. Fletcher \& J. Fitness (Eds.), Knowledge structures in close relationships: A social psychological approach (pp. 247-274). Mahwah, NJ: Erlbaum. 
Clore, G. L., Schwarz, N., \& Conway, M. (1994). Affective causes and consequences of social information processing. In R. S. Wyer \& T. K. Srull (Eds.), Handbook of social cognition (2nd ed., Vol. 1, pp. 323418). Hillsdale, NJ: Erlbaum.

Dornbusch, S. M., \& Scott, W. R. (1975). Evaluation and the exercise of authority. San Francisco: Jossey-Bass.

Ekman, P. (1993). Facial expression and emotion. American Psychologist, 48, 384-392.

Ekman, P., \& Friesen, W. V. (1975). Unmasking the face: A guide to recognizing emotions from facial clues. Englewood Cliffs, $\mathrm{NJ}$ : PrenticeHall.

Ellyson, S. L., \& Dovidio, J. F. (Eds.). (1985). Power, dominance, and nonverbal behavior. New York: Springer-Verlag.

Fiske, S. T., \& Depret, E. (1996). Control, interdependence, and power: Understanding social cognition in its social context. In W. Stroebe \& M. Hewstone (Eds.), European review of social psychology (Vol. 7, pp. 31-61). New York: Wiley.

Frank, R. H. (1985). Choosing the right pond. New York: Oxford University Press.

French, J. R. P., \& Raven, B. (1959). The bases of social power. In D. Cartwright (Ed.), Studies of social power (pp. 150-167). Ann Arbor, MI: Institute for Social Research, University of Michigan.

Funk, C. L. (1996). The impact of scandal on candidate evaluations: An experimental test of the role of candidate traits. Political Behavior, 18, 1-24.

Funk, C. L. (1997). Implications of political expertise in candidate trait evaluations. Political Research Quarterly, 50, 675-697.

Gallois, C. (1993). The language and communication of emotion. American Behavioral Scientist, 36, 309-338.

Glaser, J., \& Salovey, P. (1998). Affect in electoral politics. Personality and Social Psychology Review, 2, 156-172.

Grand jury testimony of William Jefferson Clinton [videotape]. (1998, August 17). Orlando Park, IL: MPI Home Video.

Halberstadt, A. G. (1991). Toward an ecology of expressiveness: Family socialization in particular and a model in general. In R. S. Feldman \& B. Rime (Eds.), Fundamentals of nonverbal behavior (pp. 106-160). New York: Cambridge University Press.

Hochschild, A. (1983). The managed heart. Berkeley, CA: University of California Press.

Jones, E. E., \& Pittman, T. S. (1982). Toward a general theory of strategic self-presentation. In J. Suls (Ed.), Psychological perspectives on the self (pp. 231-262). Hillsdale, NJ: Erlbaum.

Keating, C. F. (1985). Human dominance signals: The primate in us. In S. L. Ellyson \& J. F. Dovidio (Eds.), Power, dominance, and nonverbal behavior (pp. 89-108). New York: Springer-Verlag.

Kelman, H. C. (1961). Processes of opinion change. Public Opinion Quarterly, 25, 57-78.

Keltner, D., \& Buswell, B. N. (1997). Embarrassment: Its distinct form and appeasement functions. Psychological Bulletin, 122, 250-270.

Keltner, D., Young, R. C., \& Buswell, B. N. (1997). Appeasement in human emotion, social practice, and personality. Aggressive Behavior, 23, 359-374.

Kinder, D. R. (1986). Presidential character revisited. In R. R. Lau \& D. O. Sears (Eds.), Political cognition: The 19th annual Carnegie symposium on cognition (pp. 233-255). Hillsdale, NJ: Erlbaum.

Kipnis, D. (1972). Does power corrupt? Journal of Personality and Social Psychology, 24, 33-41.
Labott, S. M., Martin, R. B., Eason, P. S., \& Berkey, E. Y. (1991). Social reactions to the expression of emotion. Cognition and Emotion, 5, 397-417.

Lanzetta, J. T., Sullivan, D. G., Masters, R. D., \& McHugo, G. J. (1985). Viewers' emotional and cognitive responses to televised images of political leaders. In S. Kraus \& R. Perloff (Eds.), Mass media and political thought (pp. 50-67). Beverly Hills, CA: Sage.

Lerner, H. E. (1980). Internal prohibitions against female anger. American Journal of Psychoanalysis, 40, 137-148.

Lonner, W. J. (1980). The search for psychological universals. In H. C. Triandis \& W. W. Lambert (Eds.), Handbook of cross-cultural psychology (Vol. 1, pp. 143-204). Boston: Allyn and Bacon.

Lutz, C. A. (1990). Engendered emotion: gender, power, and the rhetoric of emotional control in American discourse. In C. A. Lutz \& L. AbuLughod (Eds.), Language and the politics of emotion (pp. 69-91). Cambridge, England: Cambridge University Press.

Marcus, G. E., \& Mackuen, M. B. (1993). Anxiety, enthusiasm, and the vote: The emotional underpinnings of learning and involvement during presidential campaigns. American Political Science Review, 87, 672685.

Markus, H. R., \& Kitayama, S. (1991). Culture and the self: Implications for cognition, emotion, and motivation. Psychological Review, 98, 224253.

Martin, J., Knopoff, K., \& Beckman, C. (1998). An alternative to bureaucratic impersonality and emotional labor: Bounded emotionality at The Body Shop. Administrative Science Quarterly, 43, 429-469.

McHugo, G. J., Lanzetta, J. T., Sullivan, D. G., Masters, R. D., \& Englis, E. G. (1985). Emotional reactions to a political leader's expressive displays. Journal of Personality and Social Psychology, 49, 1513-1529. Olweus, D. (1978). Aggression in schools. New York: Wiley.

Sidanius, J. (1993). The psychology of group conflict and the dynamics of oppression: A social dominance perspective. In S. Iyengar \& W. J. McGuire (Eds.), Explorations in political psychology (pp. 183-219). Durham, NC: Duke University Press.

Smith, C. A., \& Ellsworth, P. C. (1985). Patterns of cognitive appraisal in emotions. Journal of Personality and Social Psychology, 48, 813-838.

Sutton, R. (1991). Maintaining norms about expressed emotions: The case of bill collectors. Administrative Science Quarterly, 36, 245-268.

Tavris, C. (1989). Anger: The misunderstood emotion. (2nd ed.). New York: Simon \& Schuster.

Tiedens, L. Z., Ellsworth, P. C., \& Mesquita, B. (2000). Stereotypes of sentiments and status: Emotional expectations for high and low status group members. Personality and Social Psychology Bulletin, 26, 560575.

Weber, M. (1947). The theory of social and economic organization (T. Parsons, Ed.; A. M. Henderson \& T. Parsons, Trans.). New York: Free Press.

Winter, D. G. (1973). The power motive. New York: Free Press.

Wong, P. T., \& Weiner, B. (1981). When people ask "why" questions, and the heuristics of attributional search. Joumal of Personality and Social Psychology, 40, 650-663.

Received December 3, 1999

Revision received May 26, 2000

Accepted June 20, 2000 